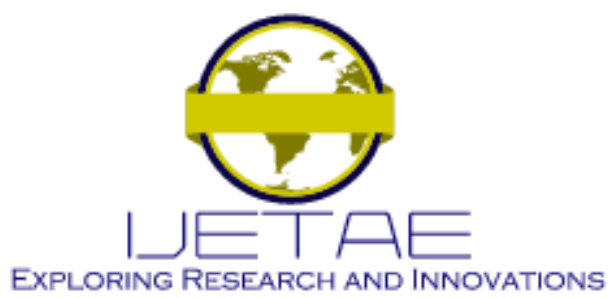

International Journal of Emerging Technology and Advanced Engineering

Website: www.ijetae.com (E-ISSN 2250-2459, Scopus Indexed, ISO 9001:2008 Certified Journal, Volume 11, Issue 11, November 2021)

Manuscript Received: 20 September 2021, Received in Revised form: 27 October 2021, Accepted: 05 November 2021

DOI: 10.46338/ijetae1121_05

\title{
Analysis and Prediction of Recorded COVID-19 Infections in the Constitutional Departments of Peru using Specialized Machine Learning Techniques
}

\author{
Enrique Lee Huamaní ${ }^{1}$, Lilian Ocares-Cunyarachi ${ }^{2}$ \\ ${ }^{1,2}$ Image Processing Research Laboratory, Universidad de Ciencias y Humanidades, Lima Perú
}

\begin{abstract}
The COVID-19 pandemic in Peru caused thousands of losses where it can be seen that until the year 2021 there are more than 200,000 deaths among men and women throughout the country. This figure is alarming and could have been avoided in time if the necessary care had been taken and the norms imposed by the Peruvian government had been followed. In the last months of the year 2020, we began to see a decrease in deaths and infected by COVID-19, which caused the public to calm down, which led to some citizens not following the biosecurity protocols, consequently causing a second wave of infected people. Therefore, it is necessary to be able to prevent a third wave since in 2021 a reduction was again visualized, which meant a reduction of deaths and infected by COVID-19, so one option to be alert to a possible third wave is to use machine learning techniques with a data set with the ministry of health to predict in which parts of the country there is the possibility of new contagions and identify which gender will be more prone to be infected in this way be aware of which parts of the country should be prioritized and thus contribute to the stability and harmony of the country.
\end{abstract}

Keywords - Covid-19; Machine Learning; Software prototype; Prediction models.

\section{INTRODUCTION}

The world changed radically due to a group of SARSCoV-2 virus internationally named as coronavirus or COVID-19 of which is an infectious disease that causes symptoms from a common cold to some very dangerous diseases such as pneumonia, Middle East respiratory syndrome (MERS) [1] and severe acute respiratory syndrome (SARS) [2].
The first reports of COVID-19 were reported on December 31, 2019 by the World Health Organization (WHO) where cases of pneumonia were found in the city of Wuhan (China) [3] for this reason at the beginning of January 2021 the authorities of the country identified this disease as the new strain of coronavirus which spread worldwide where it affected more than 200 countries [4] among them including the European continent being Italy and Spain the first foci followed among the countries of South America.

This new variation of COVID-19 not only brought cases of severe patients who were taken to intensive care but also an increase in deaths, as can be seen in the data collected worldwide by the World Health Organization [5], which shows the increase in the mortality rate. With respect to the case of deaths due to COVID-19, it can be seen thanks to the statistical analysis of [6] that the countries considered world powers were affected at the beginning of the pandemic and they were able to regulate themselves thanks to their sophisticated health systems, unlike other South American countries where the case of deaths got out of control because they did not have a specialized health system.

One of the countries where there was a large increase in the number of deaths is Peru, where it can be observed that 6 months after the pandemic began, it reached a very high rate of deaths compared to other countries in the world [6]. In the year 2021 the first vaccines will start to arrive and it is expected that by the end of this year everyone will be vaccinated with the second dose, but it should be taken into consideration that there is a probability that this will not be the case and there will still be citizens who have not been vaccinated with any dose. 


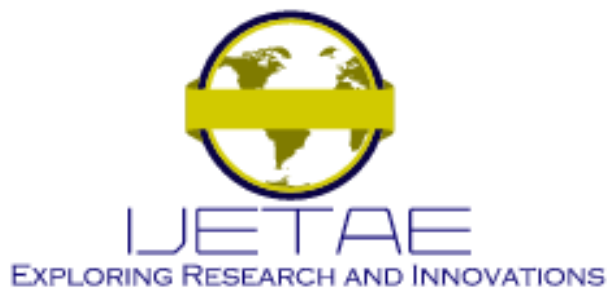

International Journal of Emerging Technology and Advanced Engineering

Website: www.ijetae.com (E-ISSN 2250-2459, Scopus Indexed, ISO 9001:2008 Certified Journal, Volume 11, Issue 11, November 2021)

One way to prevent cases of deaths from COVID-19 is to identify from the beginning in which regions of the country there is a probability of contagion and also to use tactics to prevent deaths in Peru.

In order to be able to analyze and address this issue, it is necessary to have knowledge about similar cases that address solutions regarding COVID-19. One of the ways to address and find a solution regarding the pandemic is the use of large data sets thanks to one of the branches of artificial intelligence such as Machine Learning which is a technique to mold our data set that have a logical pattern so that they can go through a predictive model and can provide solutions with a great degree of assertiveness, as can be seen in the research of [7] that uses predictive models to provide a probability of people recovered by COVID-19 based on a food diet thanks to the data set of patients from South Asia. The analysis and prediction of data is a way to find solutions for specific purposes as demonstrated by the research of [8] that also makes use of specialized Machine Learning techniques with mathematical models to give a statistical analysis of COVID-19 infected people, therefore a viable option is the use of Machine Learning to provide specific solutions using a set of data that have a logical pattern so that they can give more accurate predictions. With all that has been argued and under a critical analysis, it has been seen to find a solution to predict that can be infected again by COVID19 and this will be done thanks to Machine Learning taking as a source of analysis the data of people who have already been infected in order to prevent cases of death and also to identify which gender is the most likely to be infected.

This work is structured by a methodology section where we will talk about the tools used in this research and the steps performed for the specialized techniques of Machine Learning, we will also have a section of results and discussions where we will address what has been obtained at the end of this research and talk about improving and recommendations for this work to scale more in future work related to the world of artificial intelligence.

\section{MAterial AND Methods}

For the realization of this research, Machine Learning was used, which is a subfield of computer science and one of the branches of artificial intelligence [9] that aims to develop techniques for computers to learn under a set of data that have a pattern recognition [10].
Therefore, in this section we will discuss the tools used for the use of Machine Learning, the dataset of COVID-19 infected people from the beginning of the pandemic until April 2021 and the steps of Machine Learning techniques to have results with a high percentage of probability as shown below.

\section{A. Artificial Intelligence}

Artificial intelligence or its acronym AI is based on the faculty of the mind, which allows learning, reasoning, understanding and acquiring decision making [11]. The term artificial is defined as something that is not natural and that exists thanks to the intervention of man to be able to surpass the intensive analysis of the human being, it is defined as a field of science and engineering that is capable of making complex analysis at a potential equal or superior to the human being [12]. For this research it has been necessary to make use of artificial intelligence because as first observation it has been seen to be able to provide possible predictions of contagions by COVID-19 under a machine learning therefore it will be made use of one of its many branches as shown in Fig. 1 in it we can appreciate that one of it is the Machine Learning that will be the domain that has been used.

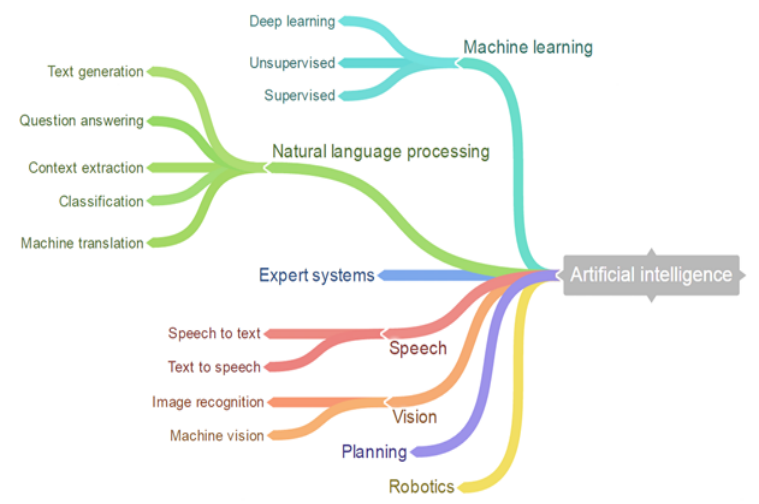

Fig. 1. Branches of artificial intelligence

The discipline of Machine Learning is a subset of artificial intelligence [13], which is in charge of improving the performance based on massive data and has been able to gain a lot of relevance in recent years due to the great increase in computing power and the boom of data because this new technique to solve problems is becoming more and more effective in the world. In Machine Learning there are different algorithms which are divided into 3 main categories. 


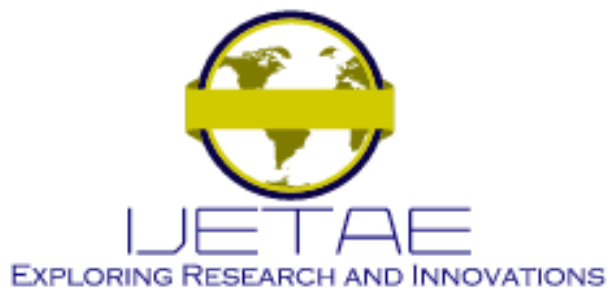

International Journal of Emerging Technology and Advanced Engineering

Website: www.ijetae.com (E-ISSN 2250-2459, Scopus Indexed, ISO 9001:2008 Certified Journal, Volume 11, Issue 11, November 2021)

\section{B. Machine Learning}

The discipline of Machine Learning is a subset of artificial intelligence [13], which is in charge of improving the performance based on massive data and has been able to gain a lot of relevance in recent years due to the great increase in computing power and the boom of data because this new technique to solve problems is becoming more and more effective in the world. In Machine Learning there are different algorithms which are divided into 3 main categories.

1)Supervised learning: This algorithm is based on a learning based on a system of labels that is associated to the data that allows them to make decisions or predictions [14]. This algorithm is the one used in this research which will be discussed in more detail about the process for learning and displaying predictive results.

2)Unsupervised learning: This algorithm does not have prior knowledge, it can be indicated that they face data chaos since their data are not $100 \%$ structured, the objective of this algorithm is to find patterns that allow them to be organized in some way [15].

3) Learning by reinforcement: In this algorithm is less used among the other 2, its purpose is to learn from one's own experience [16]. This means that it will be able to make decisions in different situations according to a trial and error process in which it is rewarded when the right decisions are made. It is currently used to enable facial recognition, medical diagnostics or classify DNA sequences.

\section{Technological tools}

For this research was developed based on certain programming languages and libraries to better interpret the data. In the world of data science you can choose from several options in this opportunity we used the programming languages and libraries mentioned below.

1) Python: It is a multiparadigm programming language that can be easily adapted to different types of projects such as object-oriented programming, imperative programming, functional programming and other areas of intensive process research such as computational parallelism under computer cluster as performed in a previous research based on high realism renderings [17]. For this reason it was considered as the main option due to the experience acquired.
2) Numpy: It is a library for the Python programming language that supports the creation of large multidimensional vectors and matrices along with a large collection of high-level mathematical functions [18]. This library will be used to defragment the data in order to structure it in a suitable way so that it can be processed by a specialized model for prediction.

3) Pandas: It is also a software library that is written as an extension of Numpy for data manipulation and analysis for the Python programming language [19]. In it you can create data structures in a very simple way giving as an advantage a cleaner and simpler work when dealing with large data sets.

4) Scikit-learn: The last library to be used is Scikit-learn, which is an automatic learning software used especially for the Python programming language. As indicated in the previous section in this work was done with Machine Learning techniques, therefore this library is vital to be able to have predictive results in a simpler way.

5) Microsoft Excel: This Microsoft office tool is mentioned because the initial data set will be in this format, so we take advantage of it to make a visual analysis of how the data is structured.

\section{Development of the research}

This section explains the steps taken for the development of the research from the quantitative understanding of the problem to the proposal of a model integrated into a system, as can be seen in Fig. 2, which shows each of the phases carried out, where the phases that require the most effort have been colored, including the preparation of the data and the proposal for integration into a system.

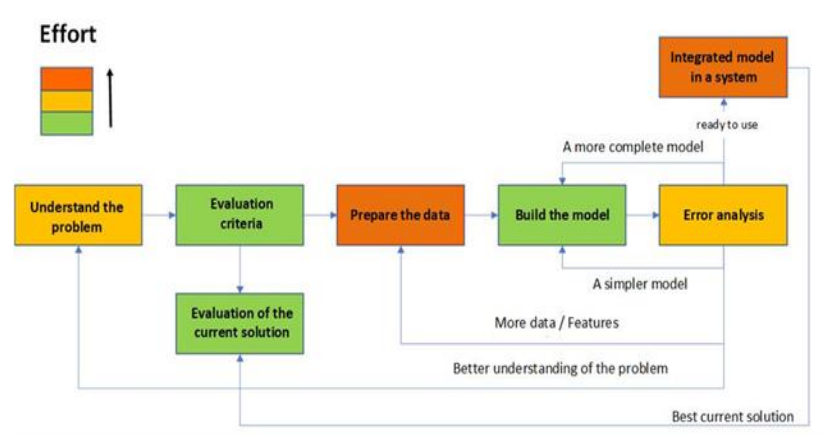

Fig. 2. Phases of Machine Learning 


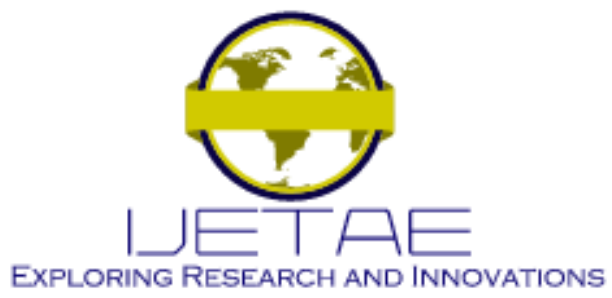

International Journal of Emerging Technology and Advanced Engineering Website: www.ijetae.com (E-ISSN 2250-2459, Scopus Indexed, ISO 9001:2008 Certified Journal, Volume 11, Issue 11, November 2021)

1) Understanding the problem: To understand the problem, it is necessary to analyze the data available to date on COVID-19 infections divided by department. A department in Peru means city. As shown in the open dataset extracted from Peru's national open data platform on June 10, 2021. Figure 3 shows in bar chart form a large number of infected where it can be seen at a glance that the largest number of infected originates in Metropolitan Lima, this is due to several factors, including the number of inhabitants of this department that reaches thanks to the data that were collected by the national census of Peru in 2020 more than 9 million inhabitants[20]. A quantitative analysis divided by each department of Peru as shown in Table 1 shows that the number of infected so far is really alarming and it is necessary to know in which regions of
Peru there is the possibility of a new outbreak as happened in December 2020 where a gigantic increase of infected people began to occur and this is caused by not giving a better treatment to the analysis of the characteristics of the population and not being able to make a predictive analysis of the occurrences. As can also be seen with respect to the data collected from the infected, there is a larger population of women who have been infected by COVID-19 with a total of 552,404 versus men with a total of 496,171 therefore there is also a need to be able to give a prediction in which regions are where women can be infected. Likewise, understanding the problem we can approach the following phases to be able to give solutions with a great margin of precision.

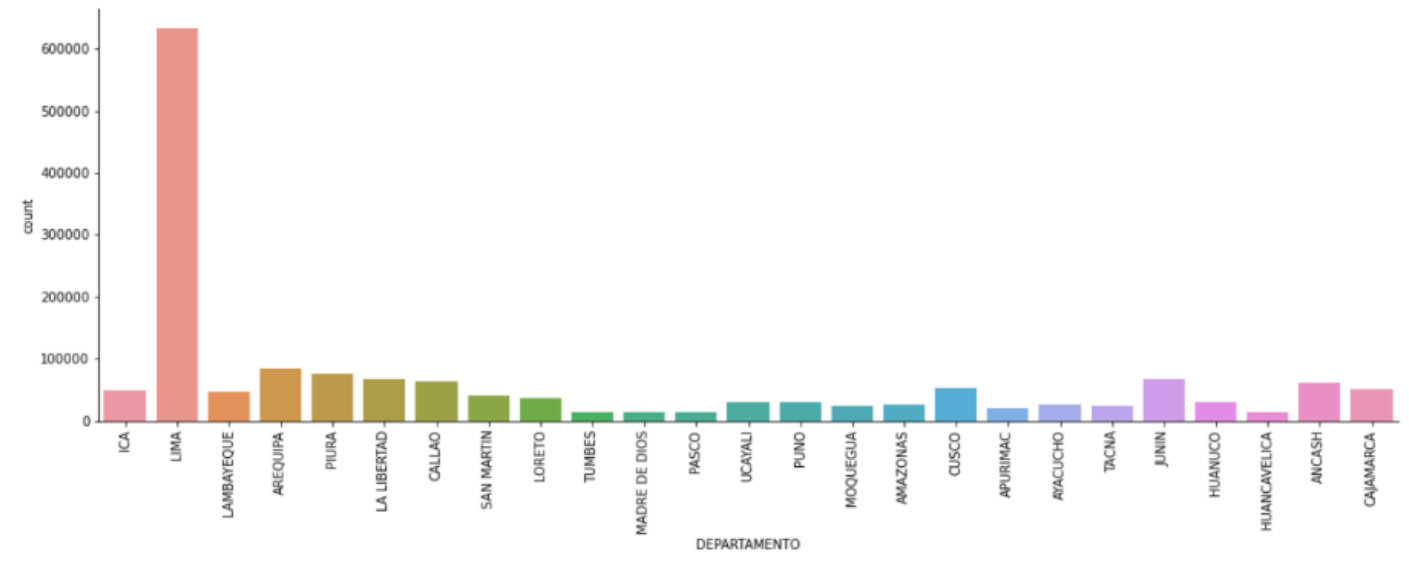

Fig. 3. Population of people infected by COVID-19 by departmen 


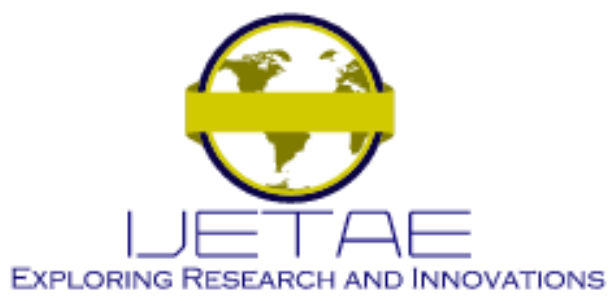

International Journal of Emerging Technology and Advanced Engineering

Website: www.ijetae.com (E-ISSN 2250-2459, Scopus Indexed, ISO 9001:2008 Certified Journal, Volume 11, Issue 11, November 2021)

TABLE I

NUMBER OF INHABITANTS INFECTED BY COVID-19 BY DEPARTMENTS

\begin{tabular}{|c|c|}
\hline Department (City) & $\begin{array}{c}\text { \# people infected by } \\
\text { COVID-19 }\end{array}$ \\
\hline LIMA & 912482 \\
\hline AREQUIPA & 103480 \\
\hline CALLAO & 97488 \\
\hline LA LIBERTAD & 83820 \\
\hline PIURA & 83003 \\
\hline JUNIN & 79523 \\
\hline ANCASH & 73418 \\
\hline CUSCO & 68262 \\
\hline CAJAMARCA & 62578 \\
\hline LAMBAYEQUE & 57733 \\
\hline ICA & 55373 \\
\hline SAN MARTIN & 46345 \\
\hline LORETO & 42064 \\
\hline PUNO & 35722 \\
\hline HUANUCO & 33878 \\
\hline UCAYALI & 31723 \\
\hline AYACUCHO & 30866 \\
\hline AMAZONAS & 30129 \\
\hline TACNA & 28016 \\
\hline MOQUEGUA & 26900 \\
\hline APURIMAC & 24906 \\
\hline TUMBES & 17597 \\
\hline HUANCAVELICA & 15346 \\
\hline PASCO & 14856 \\
\hline MADRE DE DIOS & 13543 \\
\hline
\end{tabular}

2) Definition of evaluation criteria: In order to be able to properly define our evaluation of the model to be used, a mathematical model of the mean square error (MAE) was used as an evaluation to determine whether the predictive results are correct or are far from reality, the equation used is the one shown in (1).

$$
M A E=\frac{1}{n} \sum_{i=1}^{n}\left(\hat{Y}_{i}-Y_{i}\right)^{2}
$$

3) Data preparation: As indicated in the introduction section in this research we used open data from the Ministry of Health of Peru, this data is established in a CSV format where you can see that there is incomplete data through the analysis performed, therefore the following processes were performed to have a good set of data that serves for machine learning.

a) Elimination of data with no logical meaning: Although it is not a recommended option because these data are from a survey, it was necessary to perform them since in the same analysis it could be evidenced that they did not contribute to the improvement of machine learning because they were illogical data set with nulls or numerical data set as text.

b) Imputation of data at fair value: In the data set we could see missing values because the surveys conducted could have been considered as zero values, so we have tried to give a logical meaning to certain types of values that could contribute to our learning mode.

c) Data imputation under a machine learning model: Under this research it was also possible to complete the data under the learning model to be able to complete certain empty data, a clear example was the case of gender of the participants that in a first instance the data that did not have a defined sex were eliminated from the data set, but thanks to the learning model it was possible to self-complete data that were necessary to exist thanks to the existing characteristics that gave as classification the sex of a staff, for this reason it was possible to impute data that complied with these same characteristics.

d) Proper formatting of the data: When you have the data ready, it is necessary to be able to give them a suitable format. A clear example is the age that is sometimes given in decimal form when it is clearly integer. Also in the case of the result date, therefore, it is necessary to be able to establish the appropriate format so that the learning model is efficient.

e) Use of relevant characteristics: When you have several characteristics in the data can be attributed to a benefit for the learning model to be more robust, as in other cases not. Therefore it is necessary to select the correct data because there are characteristics that before providing a benefit to our algorithm do the opposite, in TABLE 2, we show the characteristics chosen because they prove to be efficient to predict the possible infected by the gender of a person. 


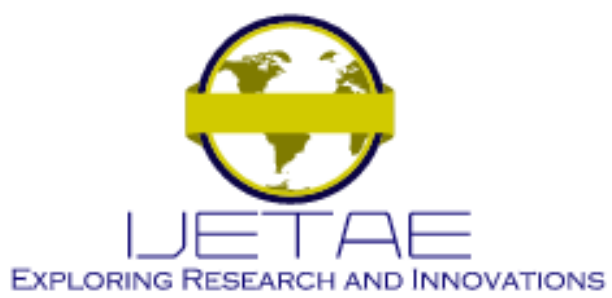

International Journal of Emerging Technology and Advanced Engineering

Website: www.ijetae.com (E-ISSN 2250-2459, Scopus Indexed, ISO 9001:2008 Certified Journal, Volume 11, Issue 11, November 2021)

TABLE II

CHARACTERISTICS

\begin{tabular}{|l|l|}
\hline Characteristic & Description \\
\hline CUT_DATE & Cut-off date of information \\
\hline DEPARTMENT & $\begin{array}{l}\text { Department where the person } \\
\text { confirmed as a covid-19 positive } \\
\text { case resides }\end{array}$ \\
\hline PROVINCE & $\begin{array}{l}\text { Province where the person } \\
\text { confirmed as a covid-19 positive } \\
\text { case resides }\end{array}$ \\
\hline DISTRICT & $\begin{array}{l}\text { District where the person confirmed } \\
\text { as a covid-19 positive case resides }\end{array}$ \\
\hline METODOX & $\begin{array}{l}\text { Laboratory method to which a } \\
\text { covid-19 test is submitted }\end{array}$ \\
\hline AGE & $\begin{array}{l}\text { Age of person confirmed as covid- } \\
19 \text { positive case }\end{array}$ \\
\hline SEX & $\begin{array}{l}\text { Sex of person confirmed as covid-19 } \\
\text { positive case }\end{array}$ \\
\hline RESULT_DATE & Date of covid-19 test result \\
\hline
\end{tabular}

f) Name of features used for machine learning: As shown in Table 2, a total of 8 characteristics will be used where the "SEX" in this occasion will be the prediction label. For the automatic learning model to be optimal, it is necessary to be able to quantify the data set because the data in text form makes the training not optimal, therefore it is necessary to make a change and convert everything in numerical form as shown in Figure 4 in the conversion of data to quantifiable form to finally convert the data to the "cat.codes" format as shown in Figure 5. With this structure carried out, the use of the model can be started so that the data shows quantifiable data.

positive_covid_data[' 'UUID'] =positive_covid_data['UUID'].astype('category' ) positive_covid_data['DXMETHOD'] =positive_covid_data['DXMETHOD'] .astype('category') positive_covid_data[ ['SEX'] =positive_covid_data['SEX'] . astype(' category') positive_covid_data[ 'DEPARTMENT'] ] positive_covid_data[ 'DEPARTMENT' ] . astype ('category' positive_covid_data['PROVINCE']=positive_covid_data['PROVINCE']. astype('category' ) positive_covid_data['DISTRICT'] =positive_covid_data['DISTRICT'] .astype('category')

Fig.4. Conversion of characteristics to quantifiable data

positive_covid_data[ 'UUID']=positive_covid_data[ 'UUID'].cat.codes positive_covid_data['SEX']=positive_covid_data['SEX'].cat.codes positive_covid_data[ 'DEPARTMENT' ] =positive_covid_data[ 'DEPARTMENT' '].cat.codes positive_covid_data['PROVINCE']=positive_covid_data['PROVINCE'].cat.codes positive_covid_data['DISTRICT'] =positive_covid_data['DISTRICT' ].cat.codes positive_covid_data[ 'DXMETHOD']=positive_covid_data[' DXMETHOD']. cat.codes

Fig.5. Conversion to cat.codes to quantifiable data

4) Model construction and data effectiveness phases: The model used is the decision tree due to its simplicity in predicting data that are prepared.
The process of the model used is explained in graphical form as shown in Fig. 6 where it is indicated that everything starts from the structured data with the characteristics already defined as indicated in Table 2, then it goes through the decision tree model and then the predictive results are obtained at that time is going through the mathematical model MAE indicated in (1) to obtain the predictive errors. Once the errors are identified, the data is refined since the model has two output data, validation and training, so the training data is refined and re-integrated into the data set and this cycle continues until the prediction results meet a high percentage of accuracy.

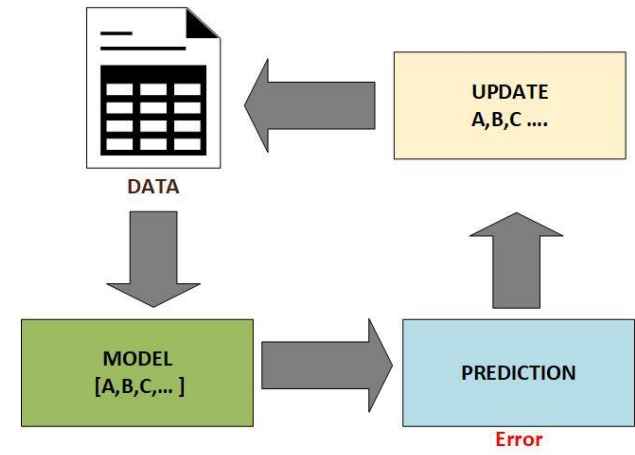

Fig.6. Model phases for good predictive data

\section{RESULTS AND DisCUSSIONS}

This section explains the predictive results obtained with the decision tree model, in which the results of the probability of new positive cases of COVID-19 will be provided, as well as determining which gender will be the most likely to be infected. It will also talk about the proposal of an integration of a mobile and web app, arguing itself the discussions and future proposals for this research.

\section{A. Predictive results under the predictive model}

As can be seen in Fig. 7, it can be verified that there is a probability of a massive increase in the number of COVID19 positive cases in the department of Lima, where the female sex (a) stands out with a total of 350,000 infected. It has also been possible to determine, thanks to the decision tree model, that a total of 40,000 new COVID-19 infections could occur in Callao. This analysis also shows that regions such as Loreto, San Martin, Ucayali and Huanuco have a predicted infection rate of 10,000 cases, but none of these cases reaches 50,000, which would be positive for the population of women in this region. 


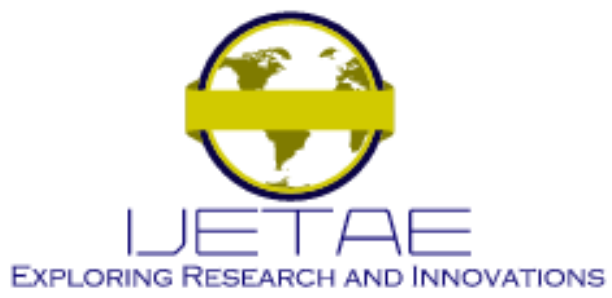

International Journal of Emerging Technology and Advanced Engineering Website: www.ijetae.com (E-ISSN 2250-2459, Scopus Indexed, ISO 9001:2008 Certified Journal, Volume 11, Issue 11, November 2021)

It can also be seen that there are regions that have a low rate of infection such as the departments of Apurimac, Pasco, Madre de Dios and Huancavelica where it is observed that the rate of infection does not exceed 5000 . Therefore, by means of this prediction model, two very important points can be indicated.

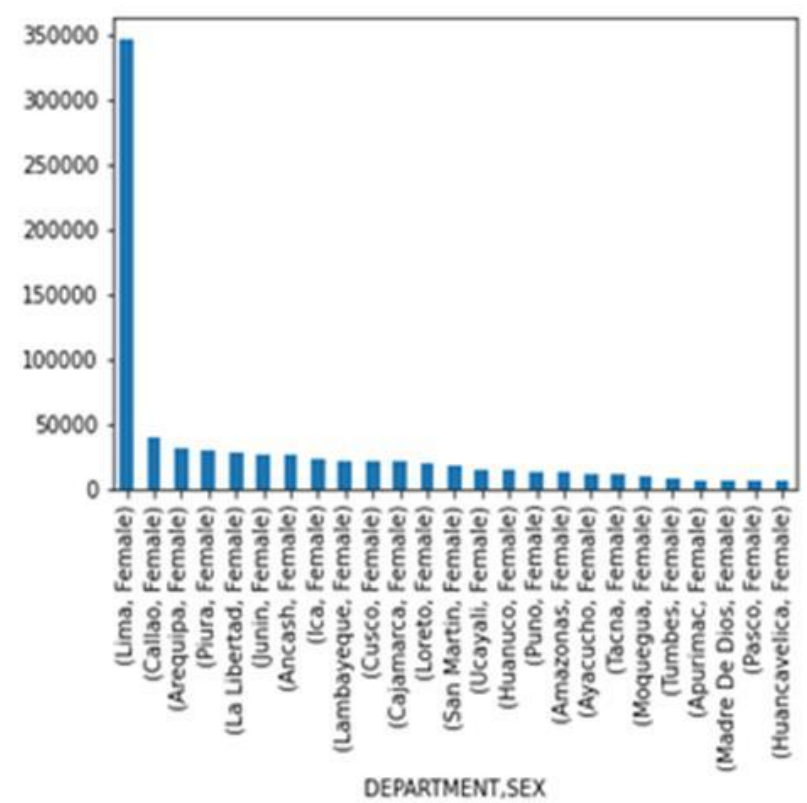

(a) Female gender
The first is that the departments that will continue to have the highest rate of infection are Lima and Callao and that the sex which is more prone to contracting the virus is female. In order to be precise in this work, the data provides an accuracy of $49.48 \%$ of occurrence, therefore, it is not necessary to be faithful to these results because certain inaccuracies will occur when this is implemented for a real study and application.

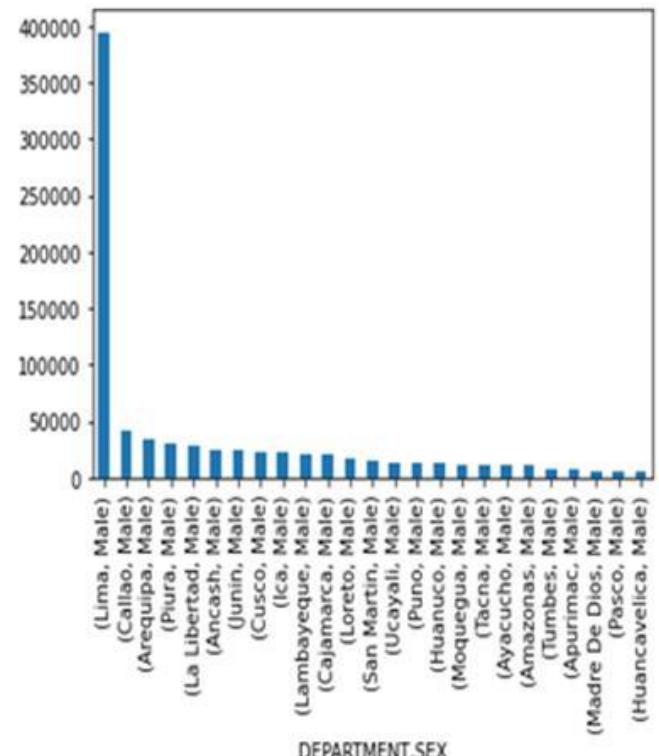

(b) Male gender

Fig.7. Predictive results of infection under male and female sex.

\section{B. Proposal for integration in a system}

One proposal under consideration is to create a web platform to interactively view possible COVID-19 cases in the departments of Peru. This proposal is still being formulated with greater robustness so that later it can be proposed for a competitive fund within Peru.
In this proposal that is still in prototype version with respect to Figure 8 shows the architecture where from the mobile and web app can consume the server through a database that is on a web platform so that this form of graphics can return the departments with more contagions and determine which sex is still the most likely to be infected. In order to generate this first prototype we have followed the following research work done by professionals in software development [21] [22] [23] [24]. 


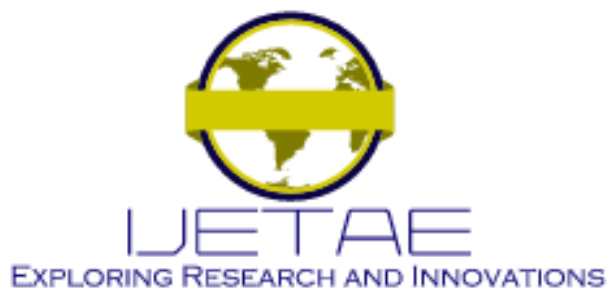

International Journal of Emerging Technology and Advanced Engineering Website: www.ijetae.com (E-ISSN 2250-2459, Scopus Indexed, ISO 9001:2008 Certified Journal, Volume 11, Issue 11, November 2021)

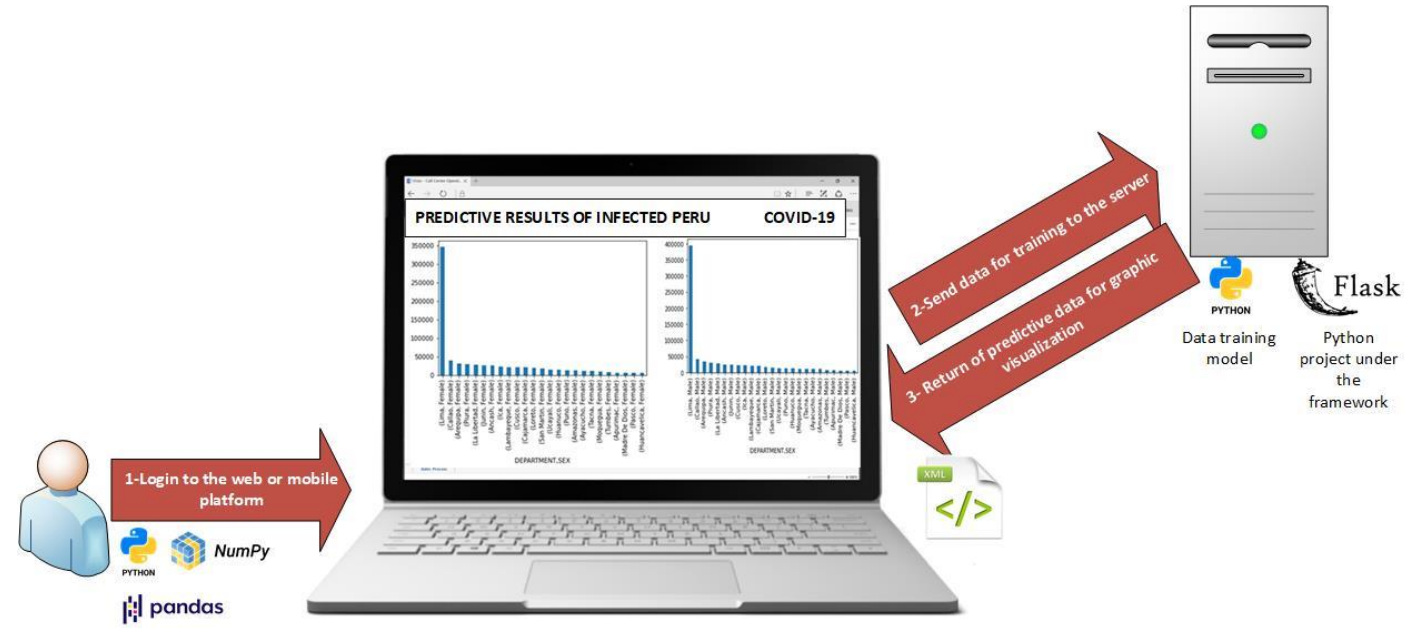

Fig. 8. Predictive results of contagion under male and female sex.

\section{CONCLUSIONS}

In this research, it is concluded that an approximation was obtained to be able to predict those infected by COVID-19 under sex and to know in which department of Peru a new outbreak may occur. It is also necessary to indicate that these results do not show a $100 \%$ accuracy, but it serves as a support to be able to provide a possible prevention to the Peruvian population through a state of emergency, because in the country the states of emergency have been classified by different levels, so when detecting early, it is possible to apply strategies in a short time.

We suggest to the scientific community that this research be taken as a reference in the steps developed in the use of Machine Learning techniques and how we have shown that they have provided a possible prediction of COVID-19 events. It should be emphasized again that the results marked an accuracy of $49.48 \%$ due to the fact that we have had to get rid of a large amount of data that could not be passed through the training processing because this information was missing or inconsistent data. Finally, it should be noted that this proposal will be taken as a basis for initiating more complex research and can be applied to a real environment.

\section{REFERENCES}

[1] H. J. Chang, "Evaluation of the basic reproduction number of MERS-CoV during the 2015 outbreak in South Korea," Int. Conf. Control. Autom. Syst., vol. 0, no. Iccas, pp. 981-984, 2016, doi: 10.1109/ICCAS.2016.7832428.

[2] Q. Wei, X. Wei, and H. Jin, "Brittleness theory and its application on the analysis of SARS," Proc. World Congr. Intell. Control Autom., vol. 1, pp. 531-535, 2006, doi: 10.1109/WCICA.2006.1712396.

[3] S. Umakanthan et al., "Origin, transmission, diagnosis and management of coronavirus disease 2019 (COVID-19)," Postgrad. Med. J., vol. 96, no. 1142, pp. 753-758, 2020, doi: 10.1136/postgradmedj-2020-138234.

[4] L. Alanagreh, F. Alzoughool, and M. Atoum, "The human coronavirus disease covid-19: Its origin, characteristics, and insights into potential drugs and its mechanisms," Pathogens, vol. 9, no. 5, 2020, doi: 10.3390/pathogens9050331.

[5] "Coronavirus disease (COVID-19) data," World Health Organization, 2021. https://www.who.int/data/gho/.

[6] E. Stein and C. Valencia, "Evolution of deaths from COVID-19 in the world per million inhabitants," John Hopkins University Coronavirus Resource Center, 2021. https://coronavirus.jhu.edu/.

[7] M. S. Hossen and D. Karmoker, "Predicting the Probability of Covid-19 Recovered in South Asian Countries Based on Healthy Diet Pattern Using a Machine Learning Approach," Int. Conf. Sustain. Technol. Ind. 4.0, pp. 19-20, 2020, doi: 10.1109/STI50764.2020.9350439.

[8] Y. Liu and Y. Xiao, "Analysis and Prediction of COVID-19 in Xinjiang Based on Machine Learning," Proc. - 2020 5th Int. Conf. Inf. Sci. Comput. Technol. Transp. ISCTT 2020, pp. 382-385, 2020, doi: 10.1109/ISCTT51595.2020.00072. 


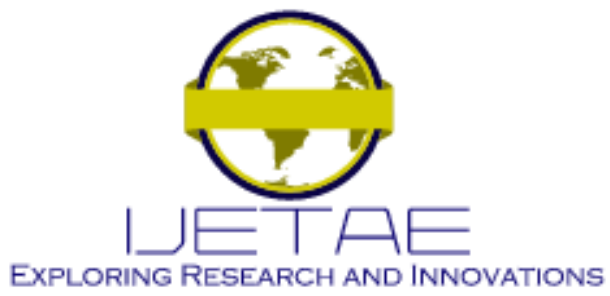

International Journal of Emerging Technology and Advanced Engineering

Website: www.ijetae.com (E-ISSN 2250-2459, Scopus Indexed, ISO 9001:2008 Certified Journal, Volume 11, Issue 11, November 2021)

[9] X. Fu, "The Application of Artificial Intelligence Technology in College Physical Education,” Proc. - 2020 Int. Conf. Big Data, Artif. Intell. Internet Things Eng. ICBAIE 2020, pp. 263-266, 2020, doi: 10.1109/ICBAIE49996.2020.00062.

[10] X. Y. Zhang, C. L. Liu, and C. Y. Suen, “Towards Robust Pattern Recognition: A Review," Proc. IEEE, vol. 108, no. 6, pp. 894-922, 2020, doi: 10.1109/JPROC.2020.2989782.

[11] Z. Li, "Analysis on the Influence of Artificial Intelligence Development on Accounting," Proc. - 2020 Int. Conf. Big Data, Artif. Intell. Internet Things Eng. ICBAIE 2020, pp. 260-262, 2020, doi: 10.1109/ICBAIE49996.2020.00061.

[12] I. Konenko, "Machine learning for medical diagnosis: History, state of the art and perspective," Artif. Intell. Med., vol. 23, no. 1, pp. 89109, 2001.

[13] K. Sharma and R. Nandal, "A literature study on machine learning fusion with IoT," Proc. Int. Conf. Trends Electron. Informatics, ICOEI 2019, vol. 2019-April, no. Icoei, pp. 1440-1445, 2019, doi: 10.1109/icoei.2019.8862656.

[14] A. Niculescu-Mizil and R. Caruana, "Predicting good probabilities with supervised learning," ICML 2005 - Proc. 22nd Int. Conf. Mach. Learn., no. 1999, pp. 625-632, 2005, doi: 10.1145/1102351.1102430.

[15] R. Raina, A. Madhavan, and A. Y. Ng, "Large-scale deep unsupervised learning using graphics processors," ACM Int. Conf. Proceeding Ser., vol. 382, 2009, doi: 10.1145/1553374.1553486.

[16] V. François-lavet et al., "An Introduction to Deep Reinforcement Learning," Found. trends Mach. Learn., vol. II, no. 3-4, pp. 1-140, 2018, doi: 10.1561/2200000071.Vincent.

[17] E. L. Huamaní, P. Condori, B. Meneses-Claudio, and A. RomanGonzalez, "Render farm for highly realistic images in a beowulf cluster using distributed programming techniques," Int. J. Adv. Comput. Sci. Appl., vol. 10, no. 11, pp. 407-411, 2019, doi: 10.14569/JJACSA.2019.0101156.
[18] T. Higuchi et al., "ClPy: A NumPy-compatible library accelerated with OpenCL," Proc. - 2019 IEEE 33rd Int. Parallel Distrib. Process. Symp. Work. IPDPSW 2019, pp. 933-940, 2019, doi: 10.1109/IPDPSW.2019.00159.

[19] S. G. Babic and K. Cetina, "Processing and visualization of collected data based on open-source tools and principles," 2020 43rd Int. Conv. Information, Commun. Electron. Technol. MIPRO 2020 Proc., $\quad$ pp. 1736-1739, 2020, doi: 10.23919/MIPRO48935.2020.9245215.

[20] "Instituto Nacional de Estadistica e Informatica." http://m.inei.gob.pe/prensa/noticias/la-poblacion-de-lima-supera-losnueve-millones-y-medio-de-habitantes-12031/ (accessed Jul. 22, 2021).

[21] L. C. Benjamin, M. V. Cinthia, A. Delgado, and E. L. Huamaní, "A mobile mapping system of all industrial oxygen sales locations and free locations in Lima - Peru," Int. J. Eng. Trends Technol., vol. 69, no. 4, pp. 76-80, 2021, doi: 10.14445/22315381/IJETT-V69I4P211.

[22] J. Ramos-Romero, J. Bartra-Lujan, A. Delgado, and E. L. Huamaní, "Prototype of a monitoring and prevention system for people vulnerable to cardiac arrest and covid-19 using IoT and SAP cloud platform,” Int. J. Eng. Trends Technol., vol. 69, no. 6, pp. 99-104, 2021, doi: 10.14445/22315381/IJETT-V69I6P214.

[23] A. Carrion-Silva, A. Reyes-Calderon, A. Delgado, and E. L. Huamaní, "Prototype of an application for capacity monitoring in places of voting to prevent the spread of Covid-19," Int. J. Eng. Trends Technol., vol. 69, no. 5, pp. 51-56, 2021, doi: 10.14445/22315381/IJETT-V69I5P209.

[24] C. Caceres-Gonzales, J. Delgado-Gomez, A. Delgado, and E. L. Huamaní, "Mobile application of Medical diagnosis with the implementation of artificial intelligence in metropolitan lima," Int. J. Eng. Trends Technol., vol. 69, no. 6, pp. 199-205, 2021, doi: 10.14445/22315381/IJETT-V69I6P229. 